\title{
Reflexiones sobre el consentimiento de persona fallecida para la donación de órganos; la incidencia de la sentencia del Tribunal Europeo de Derechos Humanos del caso Petrova v. Letonia
}

\section{Reflections on consent of organ donation from deceased person; influence of judgment of European Court of Human Rights. Case Petrova v. Latvia}

\begin{abstract}
Resumen
La prestación del consentimiento para la extracción de órganos de persona fallecida muestra evidentes diferencias frente al concepto técnico-jurídico de consentimiento informado; aunque podría encontrar cierta similitud con las exigencias propias de la obtención del llamado consentimiento por sustitución, y, en el supuesto de menores o incapaces, con el supuesto del consentimiento por representación. La legislación española, adoptando el régimen propio del entorno de los Estados pertenecientes al Consejo de Europa, ha diseñado un sistema de presunción de consentimiento salvo manifestación expresa en contrario; en el que la labor de la coordinación de trasplantes se debe dirigir a constatar si el potencial donante manifestó en vida tal oposición; en el bien entendido que no se requerirá en momento alguno una justificación o posible ponderación de los motivos de la negativa; y aunque la actuación cotidiana de las coordinaciones de trasplantes dirija su estrategia de actuación a involucrar a los pacientes en la responsabilidad y significado de tal acto de generosidad.

La STEDH de 24 de junio de 2014 (caso Petrova v Lituania), sin perjuicio de mostrar su plena conformidad con los regímenes basados en el consentimiento presunto recogidos en el Convenio de Oviedo de 4 de abril de 1997 y su Protocolo Adicional de Estrasburgo de 24 de enero de 2002, ha relacionado con el llamado derecho a la vida familiar la obligación de los poderes públicos de favorecer que la opinión de éstos pueda al menos ser tenida en cuenta antes de adoptarse la oportuna decisión.
\end{abstract}

Palabras clave: Consentimiento de persona fallecida.Donación de órganos.Tribunal Europeo Derechos Humanos. Convenio de Oviedo.

\begin{abstract}
Agreeing to the removal of organs from deceased shows obvious differences from the technical-legal concept of informed consent; though some similarity might be found with those of obtaining consent by substitution, and in the case of minors or disabled, with the assumption of consent by proxy (consent by representation). The Spanish legislation, adopting the regime itself of the environment States belonging to the Council of Europe, has designed a system of presumed consent unless specifically stated otherwise; in which the work of the transplant coordination should be directed to determine whether the potential donor expressed in life such opposition; on the understanding that at no time be required a possible justification or weight whatsoever of the reasons for the refusal; and although the daily performance of transplant coordinators direct its action strategy to involve patients in the responsibility and significance of such an act of generosity.

The JECHR of June 24, 2014 (case Petrova v Latvia), although showing full conformity with the regulations based on presumed consent contained in the Oviedo Convention of 4 April 1997 and its Additional Protocol Strasbourg 24 January 2002, has linked the so-called right to family life with the obligation of public authorities to provide the closest relatives with at least an opportunity to set out their views before an appropriate decision is adopted.
\end{abstract}

Key words: Consent of deceased person.Organ donation. European Court of Human Rights. Oviedo Convention.

\section{JL. Rodríguez Lainz}

Magistrado. Juzgado de Instrucción 4 de Córdoba.

Correspondencia:

José Luis Rodríguez Lainz

E-mail:

josel.rodriguez@poderjudicial.es

Fecha de recepción:

08.MAY.2015

Fecha de aceptación: 14.MAY.2015 
La prestación del consentimiento para la extracción de órganos de persona fallecida muestra evidentes diferencias frente al concepto técnico-jurídico de consentimiento informado; aunque podría encontrar cierta similitud con las exigencias propias de la obtención del llamado consentimiento por sustitución y, en el supuesto de menores o incapaces, con el supuesto del consentimiento por representación. La legislación española, adoptando el régimen propio del entorno de Ios Estados pertenecientes al Consejo de Europa, ha diseñado un sistema de presunción de consentimiento salvo manifestación expresa en contrario, en el que la labor de la coordinación de trasplantes se debe dirigir a constatar si el potencial donante manifestó en vida tal oposición, en el bien entendido de que no se requerirá en momento alguno una justificación o posible ponderación de los motivos de la negativa, y aunque la actuación cotidiana de las coordinaciones de trasplantes dirija su estrategia de actuación a involucrar a los pacientes en la responsabilidad y el significado de tal acto de generosidad. La STEDH de 24 de junio de 2014 (caso Petrova v. Lituania), sin perjuicio de mostrar su plena conformidad con los regímenes basados en el consentimiento presunto recogidos en el Convenio de Oviedo de 4 de abril de 1997 y su Protocolo Adicional de Estrasburgo de 24 de enero de 2002, ha relacionado con el llamado derecho a la vida familiar la obligación de los poderes públicos de favorecer que la opinión de éstos pueda al menos ser tenida en cuenta antes de adoptarse la oportuna decisión.

Desde el punto de vista tanto jurídico como de la praxis sanitaria, el llamado consentimiento informado ha evolucionado hacia su consideración como un derecho del paciente que va más allá del catálogo de derechos asistenciales que como demandante de asistencia sanitaria tiene reconocido: la previa información asistencial -arts. 4 y 5 de la Ley 41/2002, de 14 de noviembre, básica reguladora de la autonomía del paciente y de derechos y obligaciones en materia de información y documentación clínica-, y el respeto de su autonomía de decisión en función de tal información -art. 8-. La información asistencial responde a la necesidad de transmitir al paciente la información necesaria para que de modo comprensible y asequible a su capacidad intelectual, sensorial o cognitiva, tenga un conocimiento cabal sobre su estado de salud. Será en base a esa comprensión como podrá tomar una decisión fundada sobre su sometimiento a la intervención o actuación médica que se le propone, en función de los riesgos que comporta; o en su caso, elegir entre las distintas opciones que se le pudieran ofrecer -autonomía de decisión-.

Pero este aparente derecho, que pudiera no tener más vocación que la de formar parte de la interminable lista de derechos que formalmente se reconocen a los pacientes en los catálogos de derechos asistenciales, ha adquirido indiscutible trascendencia constitucional con la Sentencia del Tribunal Constitucional de 28 de marzo de 2011 -STC 37/2011, de 28 de marzo-. Conforme a dicha sentencia, tal derecho, en su doble dimensión de derecho de carácter informativo y de respeto de la decisión del paciente, atañe al derecho a la integridad física -art. 15 de la Constitución Española (CE)-, en el sentido de, en base a tal información, poderse el paciente oponer eficazmente a cualquier intervención sobre su cuerpo; supone una facultad de autodeterminación, que legitima al paciente para decidir libremente sobre las medidas terapéuticas y tratamientos que puedan afectar a su integridad -principios de la dignidad humana y del libre desarrollo de la personalidad, art. 10.1 de la CE-; y enraíza con el derecho que todos tenemos a exigir de la Administración Sanitaria la prestación asistencial que, dentro de las establecidas en el catálogo de prestaciones del Sistema Nacional de Salud, y en base a la información obtenida, pudiera correspondernos al amparo de lo establecido en el art. 43 de la CE.

Sin duda como consecuencia del impulso que ha supuesto el reconocimiento por el Tribunal Europeo de Derechos Humanos de una relación directa entre el derecho a la vida privada y el derecho al consentimiento informado, este derecho ha tenido cabida, en su consideración como derecho fundamental, en el art. 3.2,a) de la Carta de Derechos Fundamentales de la Unión Europea. Además, su implicación en nuestro Ordenamiento Jurídico ha alcanzado tal nivel que ya nadie podrá discutir que el estricto cumplimiento por parte de los profesionales sanitarios de sus deberes inherentes al respeto de esas dos dimensiones del derecho al consentimiento informado de sus pacientes se integra profundamente en el concepto de lex artis.

Pero cuando hablamos del consentimiento para la extracción de órganos destinados al trasplante procedentes de donante fallecido nos enfrentamos a diferencias evidentes que no deben ser obviadas. La primera gran diferencia existente entre los consentimientos informados propios de cualquier intervención o actuación médica y el consentimiento para la extracción de órganos, tejidos o células de persona fallecida para fines terapéuticos o científicos es, evidentemente, que su finalidad no es la de atender a una contingencia de salud de un paciente determinado. Frente al potencial donante, la medicina simplemente ha fracasado; y la finalidad del acto médico de la extracción es primordialmente salvar vidas de otras personas. Los valores jurídicos que entran en juego inciden sobre campos diversos del derecho a la salud 
y a la integridad física de la persona fallecida; para desplazarse al campo de su dignidad y respeto de sus sentimientos, ideologías o creencias, de los que, aun fallecida, sigue siendo acreedora toda persona. Además, tanto la predisposición como la oposición en vida a la posible donación de órganos pueden manifestarse, en esencia, de forma anticipada, bien mediante la formalización e inscripción de unas instrucciones previas o declaración de voluntad vital anticipada, bien haciéndolo saber expresamente a terceros, en condiciones que permitan su indagación para el supuesto en que la persona afectada pudiera verse en el ocaso de su vida ante tal disyuntiva; frente al ejemplo de un consentimiento informado que no admite más anticipación que aquellos supuestos de urgencia vital en los que el paciente pudiera no estar en condiciones de tomar una decisión por sí mismo. Por último, esta posibilidad de opción, como consentimiento o voluntad anticipada, no se ve necesariamente anudada a una ineludible información clínica por parte de profesionales sanitarios. Sin duda, cualquier persona podrá acudir a éstos o a autoridades sanitarias para recabar información sobre las condiciones y consecuencias de una posible donación de órganos en asistolia o en situación de cese irreversible de funciones encefálicas, pero para suscribir un documento de voluntad vital anticipada o para exponer a terceros la voluntad de donar o no donar órganos, el potencial donante podrá prescindir de esa información previa que debe preceder a cualquier decisión sobre una intervención médica.

El legislador nacional de 1979, sin duda alentado por el precedente de la Resolución del Comité de Ministros del Consejo de Europa (78) 29 sobre armonización de legislaciones de los Estados miembros relativas a la extracción, injerto y trasplante de sustancias humanas, apostó valientemente por un sistema de disponibilidad de órganos de personas fallecidas que operaría a modo de presunción iuris tantum, en el sentido de que procederá siempre la extracción salvo en el caso de que los donantes fallecidos hubieran dejado en vida constancia expresa de su oposición; criterio que ha sido reproducido por el RDL 9/2014 respecto de la donación de tejidos y células. Es objeto de indagación, por ello, la constatación no de si el posible donante fallecido habría mostrado su conformidad a la donación de haber estado en condiciones de exteriorizar su decisión, sino de si en tal contingencia hubiera mostrado su oposición a cederlos. No podemos hablar, por ello, en puridad, de un auténtico consentimiento por sustitución, en el que se complementara la capacidad de decisión de quien ya no puede tomarla por sí mismo, porque ya no es persona, sino de indagar la verdadera voluntad sobre la realización de un acto que nada tiene que ver con su estado de salud. Aunque, todo hay que decirlo, la práctica clínica suele optar, para evitar un impacto negativo sobre el buen funcionamiento del sistema y no causar más dolor que el ocasionado por el fallecimiento de seres queridos, por no solo indagar tal voluntad, sino allanar el camino para que familiares o allegados con quienes se contacte participen activamente en la toma de decisión sobre el aquietamiento a la extracción.

La voluntad del donante, en el sentido de su libre derecho a oponerse a la donación de sus órganos, tejidos o células una vez se produzca su fallecimiento, es vinculante frente a cualquier intento de utilización por una coordinación de trasplantes. Se trata por tanto de una decisión que el posible donante habrá de tomar según sus convicciones morales, culturales o de tradición geográfica, étnica o familiar, o su propia, simple y nuda voluntad, como predicado directo de su derecho fundamental al respeto de su dignidad e integridad física. Pero en ningún momento es lícito entrar a valorar la lógica o naturaleza de las bases en las que se fundamenta tal decisión negativa. $\mathrm{El}$ consentimiento no es en este caso más que una decisión, manifestación de voluntad, del posible donante, que habrá de producir su efecto tras su fallecimiento, cuando la actuación médica respecto del mismo ha dejado ya de tener sentido.

Cuando de menores de edad o incapacitados judicialmente se trate, sí estaríamos hablando de un consentimiento por representación claramente emparentado con el consentimiento informado para la práctica de cualquier información médica -arts. 9.1,a), párrafo segundo del RD 1723/2012, y 8.1, párrafo segundo del RDL 9/2014-. El representante legal se convierte en el legítimo titular del derecho a oponerse a la extracción de todos o parte de los órganos, tejidos o células de su representado; no obstante, para tomar esa decisión tiene pleno derecho a ser convenientemente informado sobre las circunstancias que rodean la práctica de la extracción (constatación científica del fallecimiento del posible donante, técnicas de extracción, estado en que quedará el cadáver tras la extracción, normativa sobre sanidad mortuoria...).

Sin embargo, el mecanismo de indagación de la voluntad del difunto es en buena parte coincidente con el ideado por el art. 9.1,a) de la Ley 41/2002, aunque se muestre más exhaustivo en la determinación de las fuentes de conocimiento a las que se deba acceder para tal menester. Previamente a la toma de decisión, según criterios médicos, sobre el posible destino de órganos, tejidos o células a un trasplante, debe constatarse en la medida de lo posible si la persona fallecida había manifestado en vida su 
oposición a la donación total o parcial de su cuerpo para tal menester. El art. 9.1,b) del RD 1723/2012 enumera, de hecho, estas fuentes, que concentra en la práctica de una información sumaria sobre si el posible donante hizo patente su voluntad a alguno de sus familiares o de los profesionales que le atendieron en el centro sanitario, a través de las anotaciones que los mismos hayan podido realizar en la historia clínica o en los medios previstos en la legislación vigente, así como el examen de la documentación y pertenencias personales que el difunto llevaba consigo. La norma debería ser aplicada con cierto grado de prudencia, al suponer una injerencia sobre derechos relacionados con la privacidad y dignidad de la persona fallecida y su entorno familiar más cercano. Sería por ello conveniente que el responsable de la coordinación de trasplantes, o la persona en quien delegue, recabara la presencia de familiares en tal cometido, o su consentimiento.

La misma norma, sin embargo, reconoce un concreto derecho de información a familiares del fallecido “... sobre la necesidad, naturaleza y circunstancias de la obtención, restauración, conservación o prácticas de sanidad mortuoria". Es un pequeño tributo al respeto y reconocimiento de familiares de donantes fallecidos en unos momentos tan dolorosos, destinado a dar cumplida cuenta del proceso de extracción y la repercusión que tendrá en el respeto del cuerpo del difunto, así como en los pasos posteriores a la intervención médica. Se pasa, en el supuesto en que no se hubiera producido una manifestación contraria expresada por el propio fallecido o su representante legal, en primer lugar, de la constatación de la oposición expresa a la práctica de la extracción a la indagación de cuál fuera su voluntad sobre tal extremo; y en segundo lugar, de considerar a los familiares como simples acreedores de un derecho de información sobre las circunstancias y finalidades de la donación a ser tenidos en cuenta a la hora de determinar cuál fuera la voluntad manifiesta en vida del posible donante.

La reciente STEDH, Secc. $4^{a}$, de 24 de junio de 2014 (caso Petrova v. Letonia; asunto 4605/05), pionera en materia de trasplante de órganos de donante faIlecido, ha incidido precisamente sobre el papel de los parientes cercanos o allegados en ese proceso de indagación de la voluntad de un eventual donante fallecido a la extracción de sus órganos para trasplante.

La Sra. Petrova era madre de un hijo mayor de edad que sufrió un gravísimo accidente de tráfico que le llevó, tras tres días de agonía en la UCI de un hospital, a su muerte encefálica. La coordinación de trasplantes de órganos del centro hospitalario inicia los trámites para indagar si el potencial donante había manifes- tado en vida su oposición a la donación, conforme a una legislación interna que partía de postulados similares a la legislación española. Conforme a dicha legislación, se accedió a los registros habilitados al efecto; se indagó en la historia clínica y a los profesionales que le habían atendido, y se comprobó que en su pasaporte, tal y como permitía la legislación interna, no había referencia alguna a su oposición a un eventual trasplante de órganos. Sin embargo, no encontrando ninguna referencia documentada a una eventual oposición, y no habiendo referencia en el expediente médico del paciente a la existencia de parientes cercanos, se optó por autorizar el trasplante, obviándose la realidad de que el fallecido tenía madre, y que además ni siquiera había sido informada del grave accidente de su hijo. La madre tuvo conocimiento de lo acontecido días después del fallecimiento y entierro de su hijo, decidiendo entablar acciones penales contra la coordinación de trasplantes, que finalmente fueron archivadas por no ser los hechos constitutivos de infracción criminal alguna. Agotó igualmente todas las instancias civiles y administrativas posibles en busca de un resarcimiento económico.

Al analizar el supuesto de hecho, el Tribunal de Estrasburgo comienza a mostrar su plena conformidad con regímenes legales que, como el lituano, y evidentemente el español, establecen el principio de la procedencia del trasplante como no conste la oposición del eventual donante fallecido a su práctica. La referencia al Convenio de Oviedo y al Protocolo Adicional de Estrasburgo, como representativos del sentir común de los Estados miembros del Consejo de Europa, marca la línea argumentativa del Alto Tribunal. Y esa sintonía alcanza a la consideración de los parientes como lógica y fundada fuente de conocimiento para la indagación sobre la verdadera voluntad del fallecido, que no como acreedores de un auténtico derecho a la prestación del consentimiento por derecho propio o representación del pariente fallecido. Sin embargo, en ese constante afán que le ha caracterizado a la hora de interpretar de forma tan expansiva el ambicioso art. 8.1 del Convenio Europeo para la salvaguardia de los derechos humanos y las libertades fundamentales, de 4 de noviembre de 1950 - $\mathrm{CEDH}-$, se llega a considerar, aunque con cierto grado de incertidumbre, la existencia de un derecho a expresar el consentimiento o rechazo en relación con la extracción de órganos de un pariente cercano; derecho que atañería al ámbito del respeto de la vida familiar protegido por dicho precepto. Este derecho no será concebido realmente como una ineludible necesidad de recabar el consentimiento del pariente cercano para proceder a la extracción de órganos de persona fallecida, sino como derecho a expresar su 
voluntad en relación con la posible extracción, en los términos expresados por la legislación lituana. En definitiva, la opción del llamado consentimiento presunto, tan arraigado en la posición común de los Estados miembros del Consejo de Europa, es plenamente respetuosa del derecho a la vida privada y familiar reconocido por el art. 8.1 del CEDH. Sin embargo, reconocidos tales ciertos derechos en favor de los parientes cercanos, referentes a la información sobre la existencia de una situación clínica favorable a la posible extracción de órganos y a la posibilidad de manifestar su consentimiento u oposición, o al menos su opinión sobre cuál era a tal respecto la verdadera voluntad del posible donante fallecido, deben articularse a nivel normativo y de actuación administrativa los medios a través de los cuales los parientes cercanos puedan ejercerlos. Precisamente en esa indefinición normativa es en la que se centra el Alto Tribunal para reconocer a la Sra. Petrova un derecho indemnizatorio como consecuencia de la transgresión de su derecho al respeto de su vida familiar.

La ley española sí reconoce ese derecho a nivel informativo, que alcanza igualmente a la posibilidad que tienen los parientes cercanos de expresar su opinión sobre la posible donación de órganos de su familiar fallecido; por lo que la normativa española, y más con la práctica habitual de los protocolos de actuación de las coordinaciones de trasplantes, con total seguridad podría superar ese control de calidad de la norma habilitante exigido por el apartado 2 del mismo precepto. Sin embargo, la sentencia representa un claro llamamiento a forzar las líneas de indagación sobre la existencia de parientes cercanos 0 allegados a los efectos de lo previsto en el mencionado art. 9.1,b) del RD 1723/2012. Y ello supone, al menos en mi opinión, no cerrar ese deber de información exclusivamente a los familiares presentes en el centro hospitalario, como refiere el párrafo segundo de dicho apartado, sino, forzando al máximo la interpretación contextual de la norma, agotar las vías de indagación para lograr contactar con esos parientes para que puedan ejercer ese derecho de raigambre informativa y de audiencia, estén o no en ese momento en las instalaciones del hospital donde se encuentre el cuerpo del eventual donante. Acudir a las Fuerzas y Cuerpos de Seguridad para tratar de lograr contactar con parientes debería ser una de las vías adecuadas para intentar obtener información sobre esos familiares, interesados sin duda no solo en saber la triste situación clínica de su ser querido, sino en hacerse también partícipes de tan importante y trascendental decisión.

En Córdoba, a 24 de febrero de 2015 